\title{
Controlled self-assembly of modified aromatic amino acids
}

Vivekshinh Kshtriya ${ }^{a}$, Bharti Koshti ${ }^{a}$, Hanuman Narode ${ }^{a}$, Soumick Naskar ${ }^{a}$, Nidhi Gour ${ }^{a}$ *

${ }^{a}$ Department of Chemistry, School of Science, Indrashil University, Kadi, Mehsana,

Gujarat, 382740, India; Email: gournidhi@gmail.com; nidhi.gour@indrashiluniversity.edu.in

\begin{abstract}
We report the self-assembly of carbobenzoxyphenylalanine (Z-Phe-OH), carbobenzoxytryptophan (Z-Trp-OH), carbobenzoxytyrosine (Z-Tyr-OH) and $N-(9-$ Fluorenylmethoxycarbonyl)-O-tert-butyl-L-tyrosine (Fmoc-Tyr(tbu)-OH) to well-defined morphologies such as fibers, spherical and flower-like self-assembled structure. The selfassembled structure formed by modify single amino acids were characterized through various microscopic and spectroscopic techniques. The self-assembled structure formation was studied extensively under varying concentrations and temperature and the mechanism of selfassembled structure formation was extensively studied through solution state ${ }^{1} \mathrm{H}$ NMR. The self-assembly studies on modified amino acid provide an important avenue for the simple fabrication and design of novel materials with immense applications. Hence, Z-Phe-OH, ZTrp-OH, Z-Tyr-OH, and Fmoc-Tyr(tbu)-OH self-assembly studies may be a pertinent extension in this direction.
\end{abstract}

Keywords: Self-assembly; modified amino acid; varying concentration; varying temperature; spheres, fibers.

\section{Introduction}

Gazit and coworkers for the very first time reported the formation of well-ordered tubular structures by dipeptide diphenylalanine (FF) and used it for the fabrication of silver nanowires. ${ }^{1}$ Following, this research the group has studied extensively the self-assembling 
behaviour of short aromatic peptides and suggested the crucial role of aromatic stackings in their self-assembly. ${ }^{2}$ The group further reported amyloid-like self-assembled structure formed by Boc-Phe-Phe-COOH, Z-Phe-Phe-COOH, and Fmoc-Phe-Phe-COOH. ${ }^{3}$ Panda et al. reported self-assembly of $\mathrm{N}$-(tertButoxycarbonyl)-S-trityl-L-cysteine to nanobowls type of structure which can be used for the anticancer drug delivery. ${ }^{4}$ In the past few decades, there has been a considerable amount of research which is pursued in single amino acids and modified single amino acids. ${ }^{5-12}$ In this context, Gazit et al reported amyloid-like structure formed by phenylalanine, ${ }^{5}$ tyrosine $^{6}$, and tryptophan. ${ }^{7}$ Sarkar et al. reported the fibrillar structure of glycine. ${ }^{13}$ Wangoo and co-workers demonstrated the self-assembly of aromatic single amino acids, ${ }^{14-16}$ and studied them extensively via various biophysical assays such as FTIR, NMR, TGA, and XRD. ${ }^{8,9,13,14}$

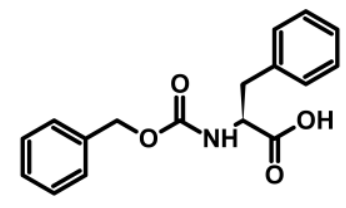

Z-Phe-OH

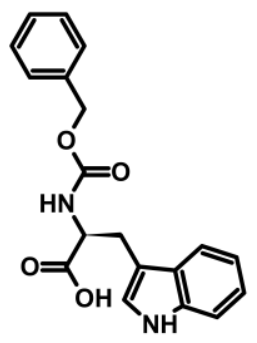

Z-Trp-OH<smiles>O=C(N[C@@H](Cc1ccc(O)cc1)C(=O)O)OCc1ccccc1</smiles>

Z-Tyr-OH

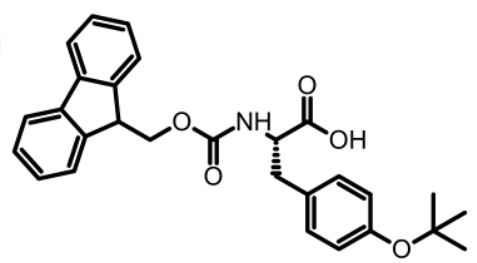

Fmoc-O-tert-butyl-L-Tyr

Scheme 1: Chemical structure of Z-Phe-OH, Z-Trp-OH, Z-Tyr-OH, and Fmoc-Tyr(tbu)OH.

Since our group has been working on the molecular self-assembly and assessing the selfassembly of the single amino acids, ${ }^{8,9}, 17,18$ modified single amino acids, ${ }^{19}$ peptides, ${ }^{20-26}$ nanoparticle/nanomaterial, ${ }^{27-29}$ and heterocyclic ${ }^{30-35}$ compounds. Our group reported for the very first time the amyloid-like self-assembled structure formed by the non-aromatic single amino acid cysteine and methionine ${ }^{8}$. Recently our group has also reported the amyloid-like structure formed by proline and hydroxyproline. ${ }^{9}$ Hence, from their study we were motivated to assess the self-assembling propensity of Z-Phe-OH, Z-Trp-OH, Z-Tyr-OH, and FmocTyr(tbu)-OH. Our study revealed that Z-Phe-OH gives a fiber-like self-assembled structure 
at room temperature and at higher temperature near $70{ }^{\circ} \mathrm{C}$, while $\mathbf{Z}$-Trp-OH gives the bunch of flowers like self-assembled structure at room temperature which on heating at $70{ }^{0} \mathrm{C}$ becomes more distinct. However, Z-Tyr-OH do not form any self-assembled structure at lower and higher concentrations at room temperature and on heating as well, FmocTyr(tbu)-OH, on the other hand forms a sphere-like self-assembled structure at room temperature while on heating at $70{ }^{\circ} \mathrm{C}$ there is a morphological transition from sphere to fibers.

\section{Result and Discussion}

Our group has been interested to study the self-assembly of single amino acids and modified single amino acids. Hence, we studied the self-assembling properties of Z-Phe-OH, Z-TyrOH, Z-Trp-OH, and Fmoc-Tyr(tbu)-OH under various concentration and temperature. A $20 \mathrm{mM}$ stock solution of Z-Phe-OH, Z-Tyr-OH, and Z-Trp-OH was prepared in $50 \%$ aqueous methanol, while the stock solution of Fmoc-Tyr(tbu)-OH prepared in only methanol due to its lower solubility. The self-assembly studies were done by diluting the stock solution in deionized water at various concentrations. The self-assembled morphology of Z-Phe-OH, Z-Tyr-OH, Z-Trp-OH and F-moc-Tyr(tbu)-OH were studied from the 1 to $10 \mathrm{mM}$ concentration range.

Z-Phe-OH (3mM) self-assemble to dense fibre like structures under all concentrations and temeperature. We cannot observe any morphological change under varying concentration and temperature (Figure 1). The fibres have non crystalline nature as can be assessed by phase contrast microscopy (Figure 2).. The fibres also bind ThT dye (Figure 3). 

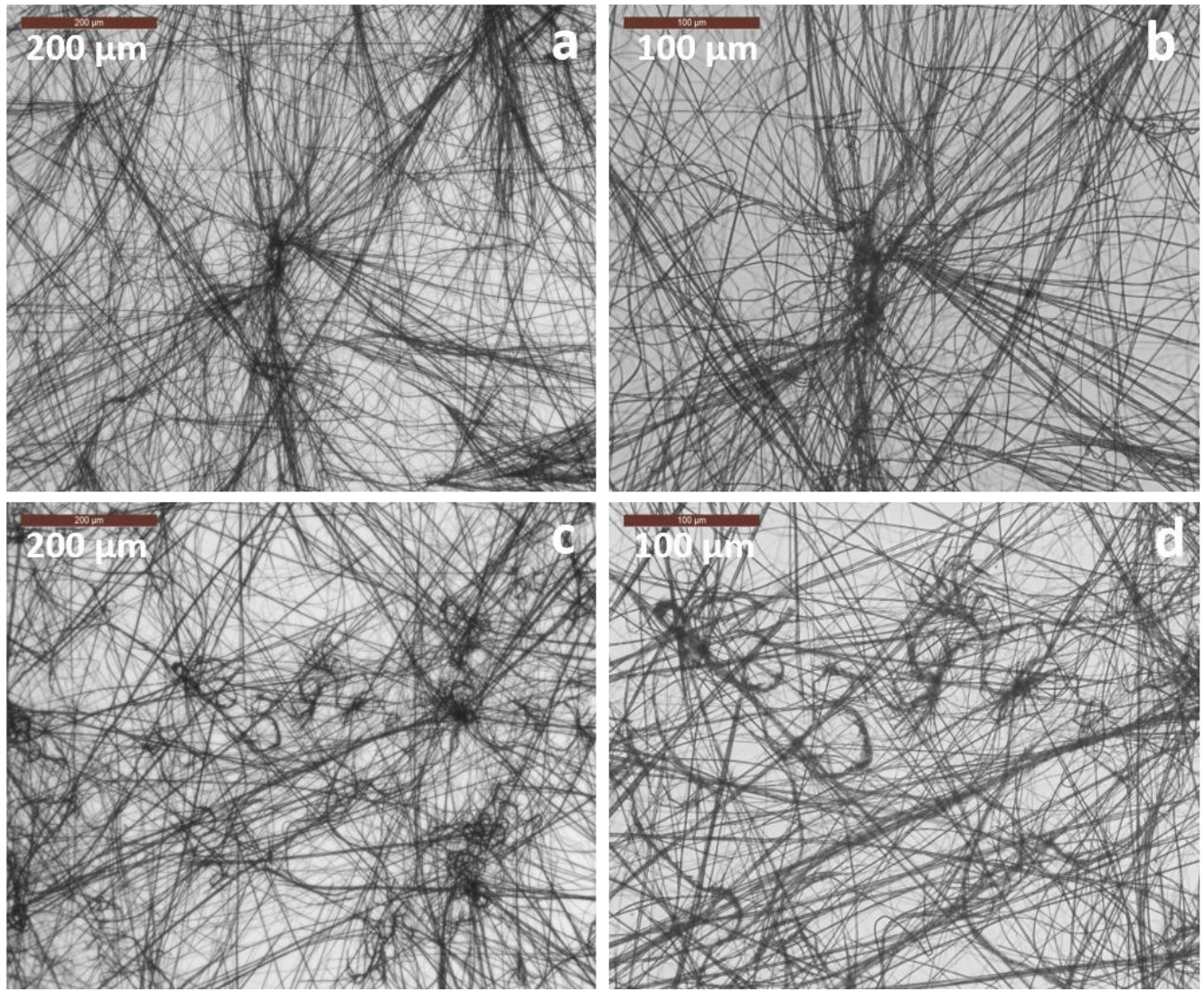

Figure 1: Optical microscopy images of self-assembled structure of Z-Phe-OH at $3 \mathrm{mM}$ concentration (a) at room temperature under 10X, scale bar $200 \mu \mathrm{m}$; (b) at room temperature under 20X, scale bar $100 \mu \mathrm{m}$; (c) at $70{ }^{\circ} \mathrm{C}$ under $40 \mathrm{X}$, scale bar $50 \mu \mathrm{m}$; (d) at $70{ }^{\circ} \mathrm{C}$ under $63 \mathrm{X}$, scale bar $20 \mu \mathrm{m}$.
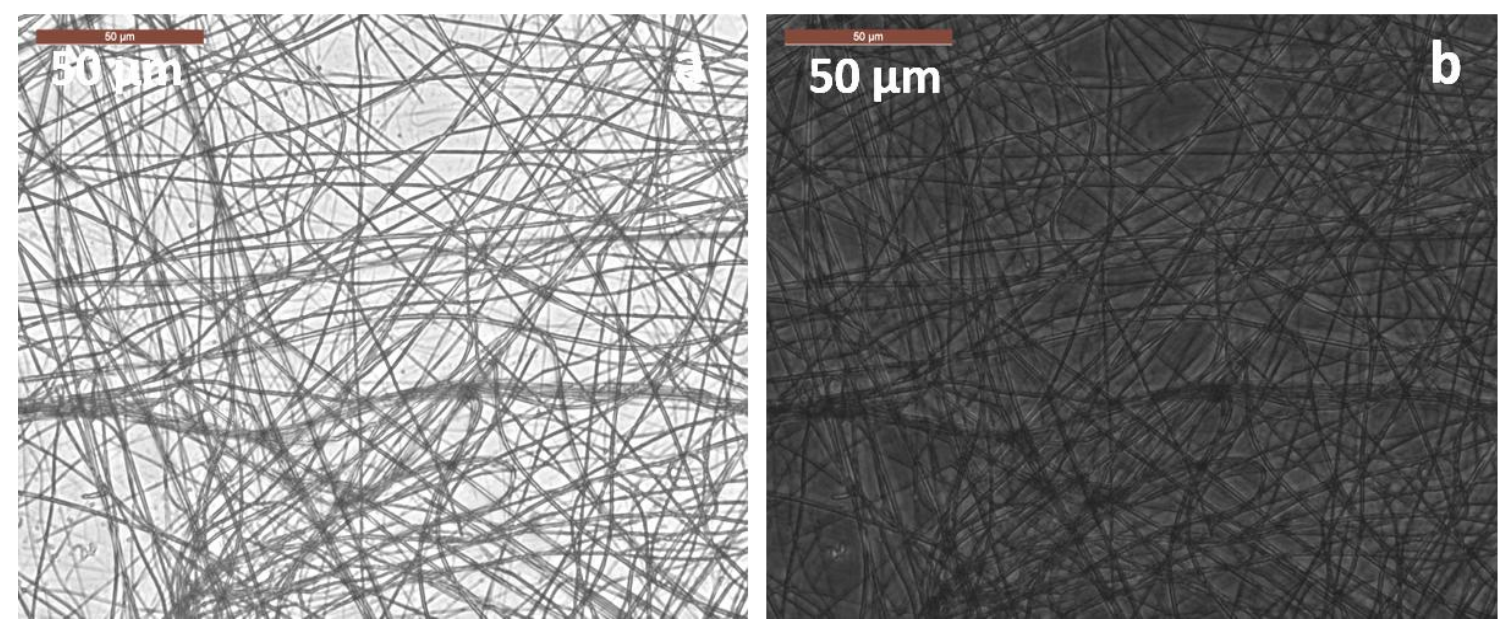

Figure 2: Microscopy image of Z-Phe-OH at $3 \mathrm{mM}$ (a) under bright field; (b) under phase contrast. 

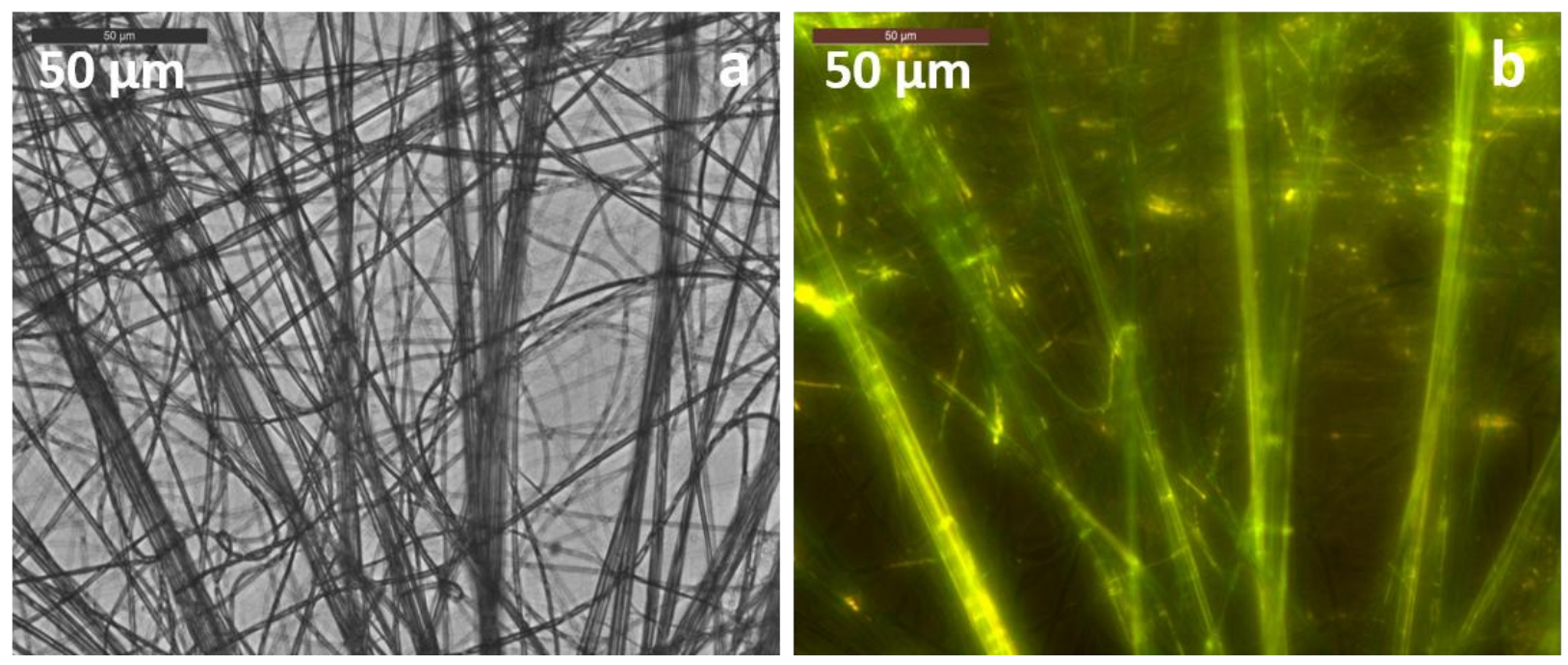

Figure 3: ThT binding with Z-Phe-OH aggregates (a) under bright field; (b) in the green filter.

The self-assembled structure of the other modified aromatic amino acid Z-Trp-OH was also studied and it revealed flower-like morphologies. At room temperature, Z-Trp-OH formed the bunch of flowers while at the higher temperature these bunch of flowers may be converted into distinct flower and more clarity could be observed in the self-assembled structure. To compare the morphologies formed by the self-assembly of Z-Phe-OH and ZTrp-OH, we were motivated to assess the self-assembly of Z-Tyr-OH too. However, in ZTyr-OH we could not observe any assembly under varying concentration or temperature. This may be because of free -OH group in Z-Tyr-OH which is absent from both Z-Phe-OH and Z-Trp-OH, The extra-OH group might destabilize the pi-pi stacking interaction which are operating in case of $\mathbf{Z}$-Tyr-OH which is the main force responsible for inducing selfassembly in aromatic amino acids. Hence, we also studied the self-assembly of F-mocTyr(tbu)-OH to assess if it could form self-assembly. 


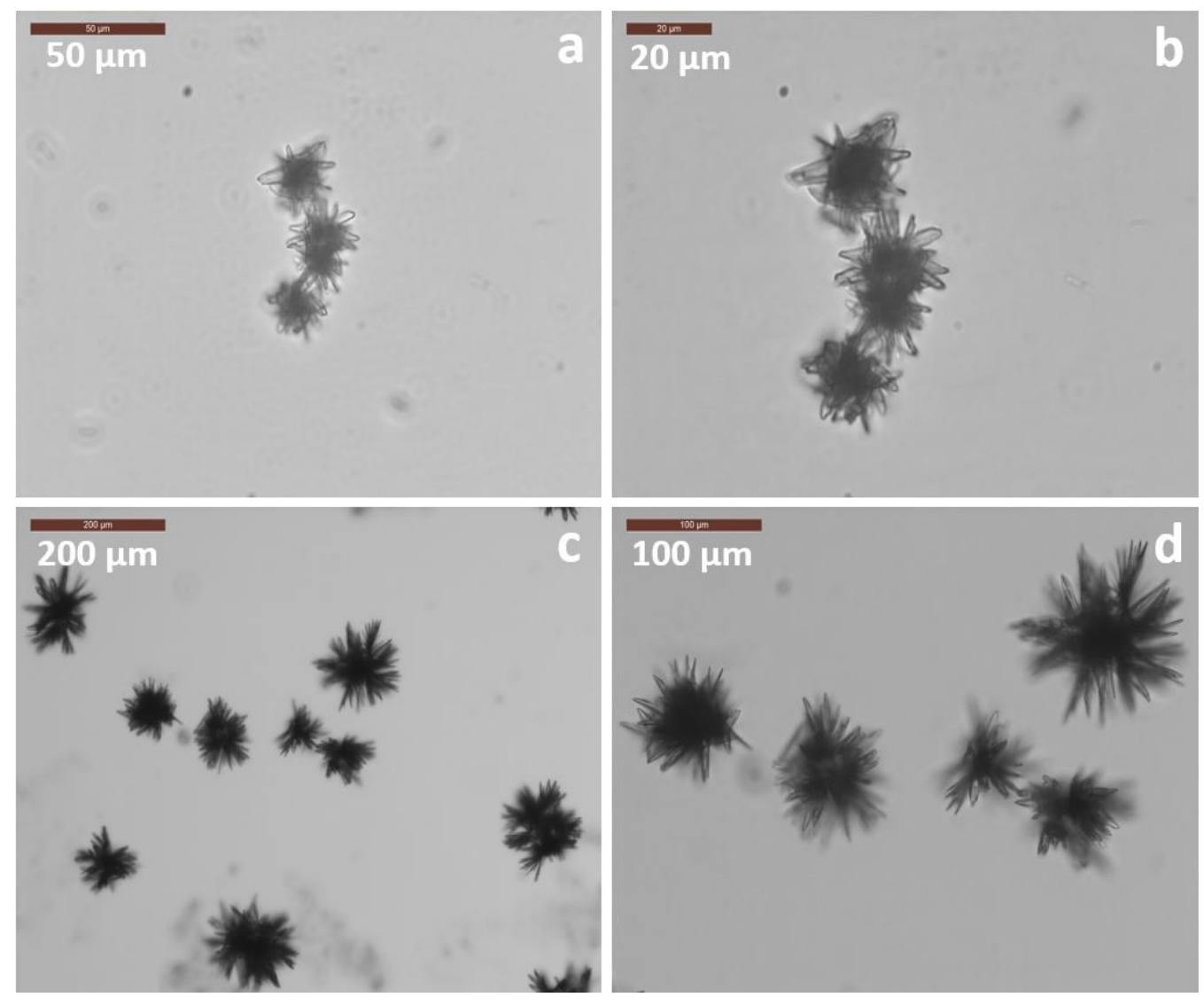

Figure 5: Optical microscopy images of self-assembled structure of Z-Trp-OH (3mM) at room temperature in water different magnification (a) under $40 \mathrm{X}$, scale bar $50 \mu \mathrm{m}$; (b) under $63 \mathrm{X}$, scale bar $20 \mu \mathrm{m}$; Heating at $70{ }^{\circ} \mathrm{C}$ (c) under $10 \mathrm{X}$, scale bar $200 \mu \mathrm{m}$; (d) under $20 \mathrm{X}$, scale bar $100 \mu \mathrm{m}$. 


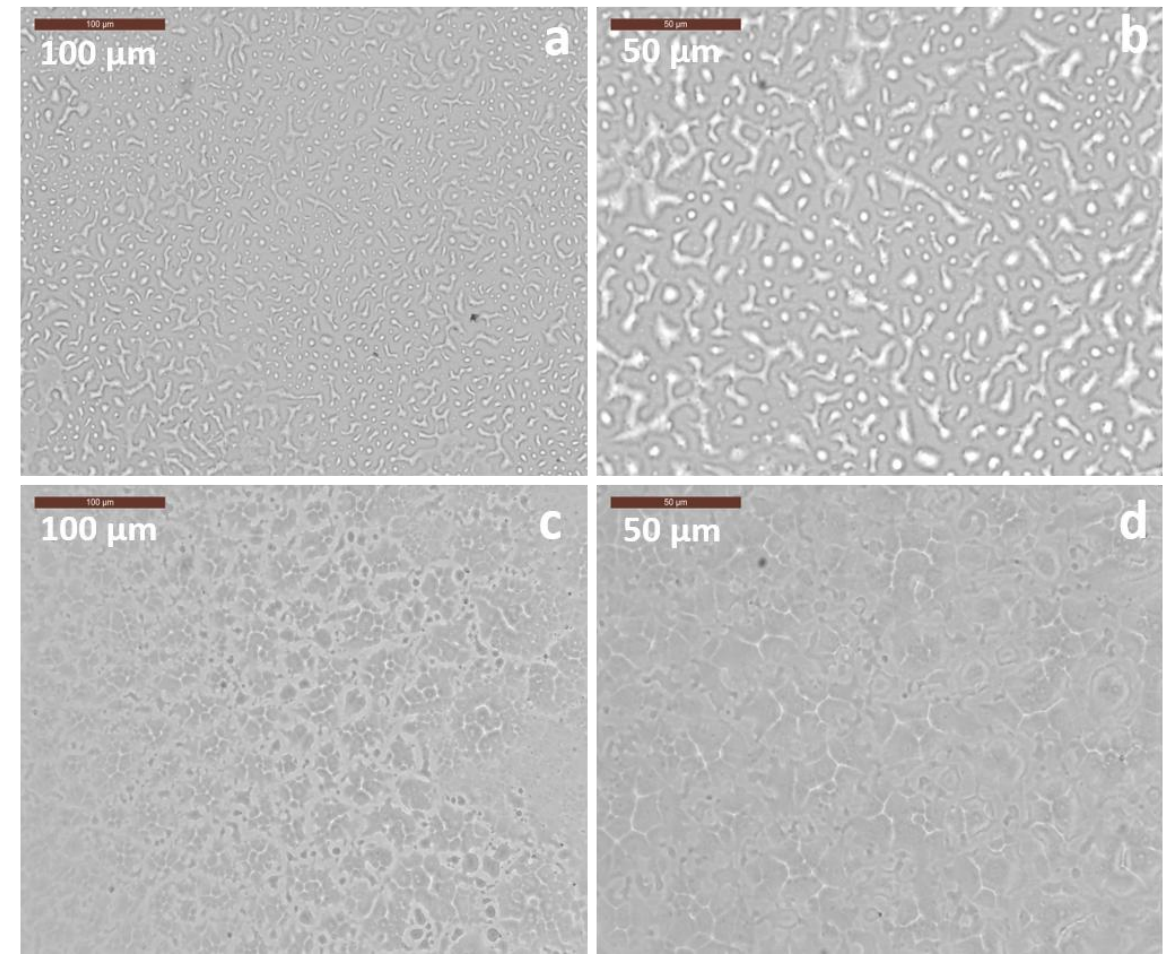

Figure 6: Optical microscopy images of self-assembled structure of Z-Tyr-OH (3mM) at room temperature in water different magnification (a) under $40 \mathrm{X}$, scale bar $50 \mu \mathrm{m}$; (b) under $63 \mathrm{X}$, scale bar $20 \mu \mathrm{m}$; Heating at $70{ }^{\circ} \mathrm{C}$ (c) under $10 \mathrm{X}$, scale bar $200 \mu \mathrm{m}$; (d) under $20 \mathrm{X}$, scale bar $100 \mu \mathrm{m}$.

Interestingly, F-moc-Tyr(tbu)-OH $(5 \mathrm{mM})$ forms sphere-like assemblies at room temperature which may be converted to fibers-like structure on heating at $70{ }^{0} \mathrm{C}$. As the concentration was increased the thickness and the density of the nano/microtubes kept on increasing without leading to any morphological transition in Z-Phe-OH. Moreover, FmocTyr(tbu)-OH we could not see any fibril formation at the concentration below $5 \mathrm{mM}$. In the case of Fmoc-Tyr(tbu)-OH, it formed a destructive aggregate at lower concentration instated of fibrils structure. We can observe which may be combined and formed the self-assembled fibrils at $5 \mathrm{mM}$ concentration.

Further, the phase-contrast study also supports the fibrils would be amorphous in nature because crystalline material would be easily seen under phase-contrast microscopy. Interestingly, Z-Phe-OH assemblies could also bind with Thioflavin T (ThT) and fibers show green fluorescence indicating efficient binding. 

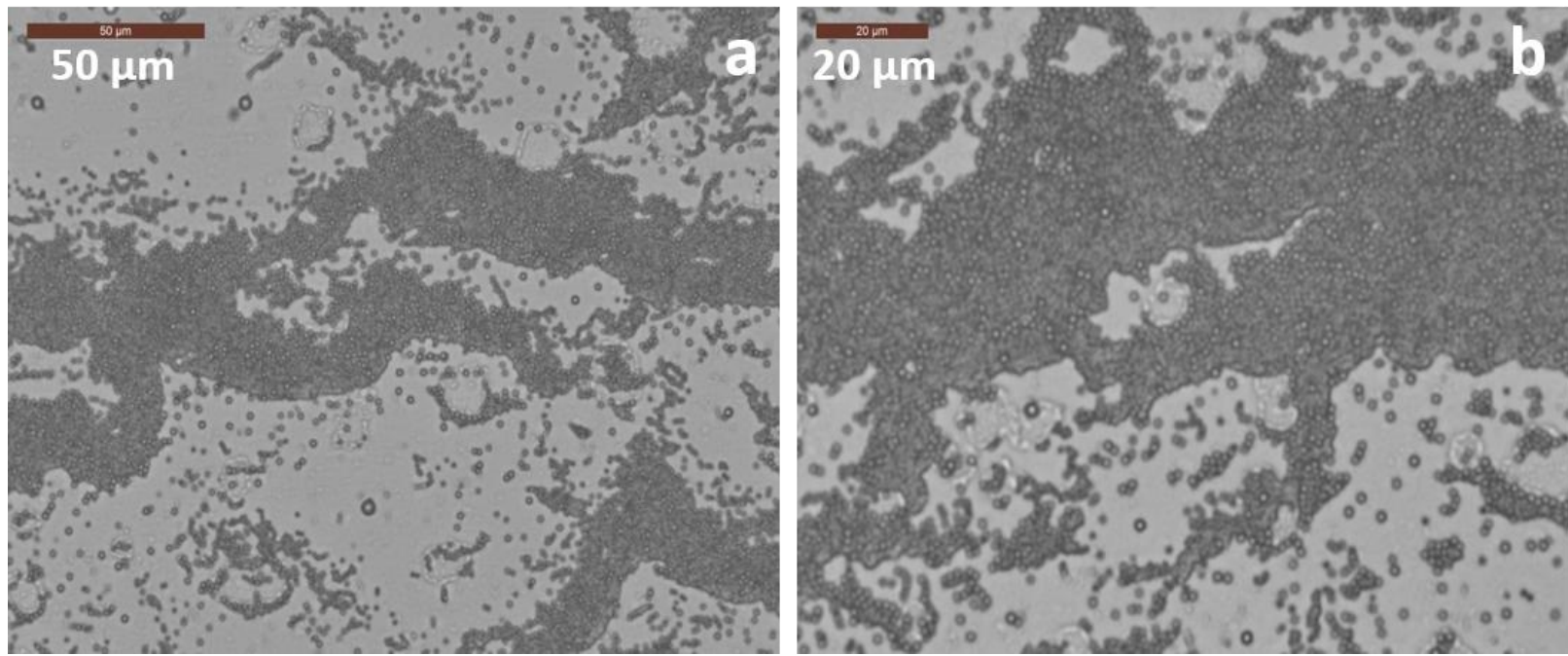

Figure 7: Optical microscopy images of the self-assembled structure of Fmoc-Tyr(tbu)-OH at $5 \mathrm{mM}$ concentration under different magnification at room temperature (a) under $40 \mathrm{X}$, scale bar $50 \mu \mathrm{m}$; (b) under $63 \mathrm{X}$, scale bar $20 \mu \mathrm{m}$.
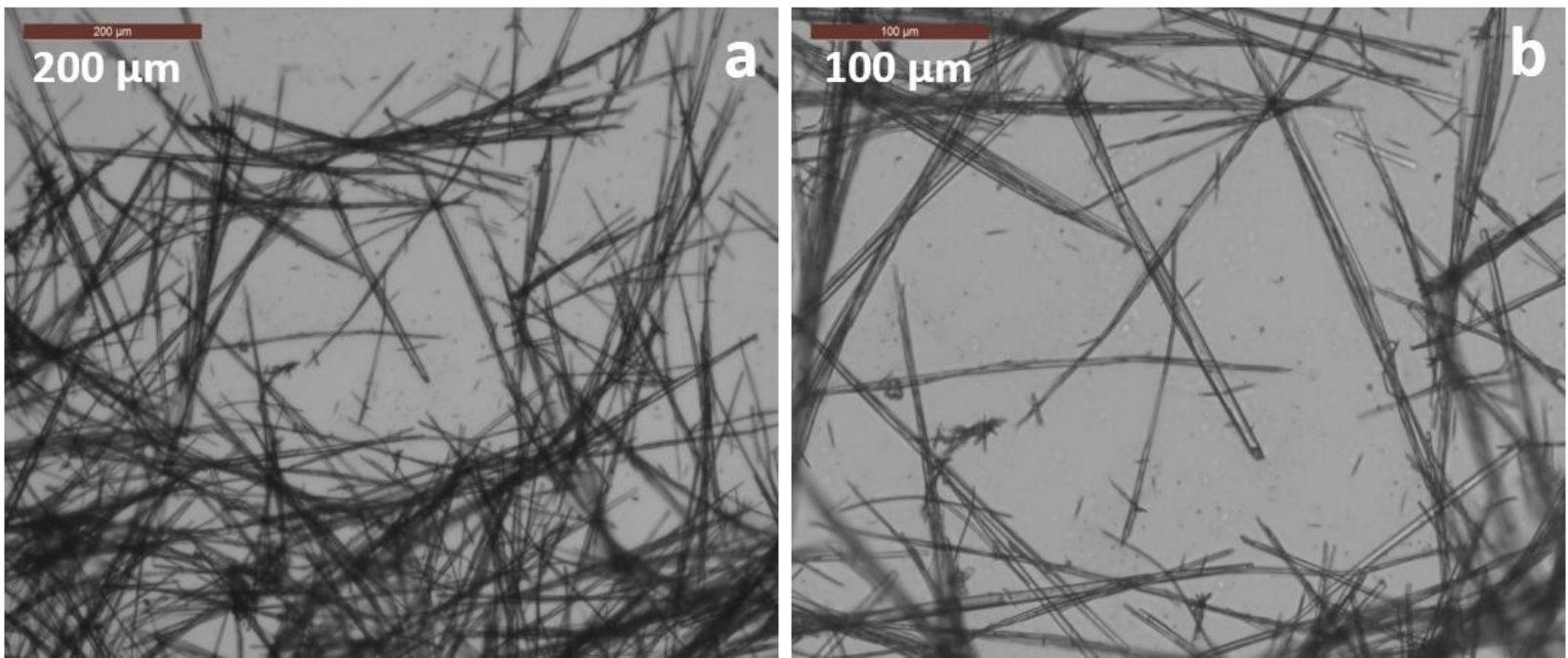

Figure 8: Optical microscopy images of self-assembled structure of Fmoc-Tyr(tbu)-OH at 5 $\mathrm{mM}$ concentration under different magnification at $70{ }^{0} \mathrm{C}$ (a) under $10 \mathrm{X}$, scale bar $200 \mu \mathrm{m}$; (b) under 20X, scale bar $100 \mu \mathrm{m}$.

Table 1: Describe the recap of the self-assemble structure formed by Z-Phe-OH, Z-TyrOH, Z- and Fmoc-Tyr(tbu)-OH in different conditions.

\begin{tabular}{|c|c|c|c|}
\hline Name of sample & Concentration & Morphology & Temperature \\
\hline Z-Phe-OH & Lower concentration & Fibrils & RT \\
\hline
\end{tabular}




\begin{tabular}{|c|c|c|c|}
\hline Z-Phe-Oh & Higher concentration & dense fibrils & $\mathrm{RT}$ \\
\hline Z-Phe-OH & Lower concentration & Fibrils & $70{ }^{0} \mathrm{C}$ \\
\hline Z-Phe-Oh & Higher concentration & dense fibrils & $70{ }^{0} \mathrm{C}$ \\
\hline Z-Tyr-OH & Low concentration & $\begin{array}{c}\text { Assembly not } \\
\text { observed }\end{array}$ & RT \\
\hline Z-Tyr-OH & Higher concentration & $\begin{array}{c}\text { Assembly not } \\
\text { observed }\end{array}$ & RT \\
\hline Z-Tyr-OH & Lower concentration & $\begin{array}{c}\text { Assembly not } \\
\text { observed }\end{array}$ & $70{ }^{\circ} \mathrm{C}$ \\
\hline Z-Tyr-OH & Higher concentration & $\begin{array}{c}\text { Assembly not } \\
\text { observed }\end{array}$ & $70^{\circ} \mathrm{C}$ \\
\hline Z-Trp-OH & Low concentration & Flower & RT \\
\hline Z-Trp-OH & Higher concentration & Flower & RT \\
\hline Z-Trp-OH & Lower concentration & Bunch of flowers & $70^{\circ} \mathrm{C}$ \\
\hline Z-Trp-OH & Higher concentration & Bunch of flowers & $70^{\circ} \mathrm{C}$ \\
\hline Fmoc-Tyr(tbu)-OH & Lower concentration & $\begin{array}{c}\text { Assembly not } \\
\text { observed }\end{array}$ & RT \\
\hline Fmoc-Tyr(tbu)-OH & Higher concentration & Spheres & RT \\
\hline Fmoc-Tyr(tbu)-OH & Lower concentration & $\begin{array}{c}\text { Assembly not } \\
\text { observed }\end{array}$ & $70^{\circ} \mathrm{C}$ \\
\hline Fmoc-Tyr(tbu)-OH & Higher concentration & Fibrils & $70^{\circ} \mathrm{C}$ \\
\hline
\end{tabular}



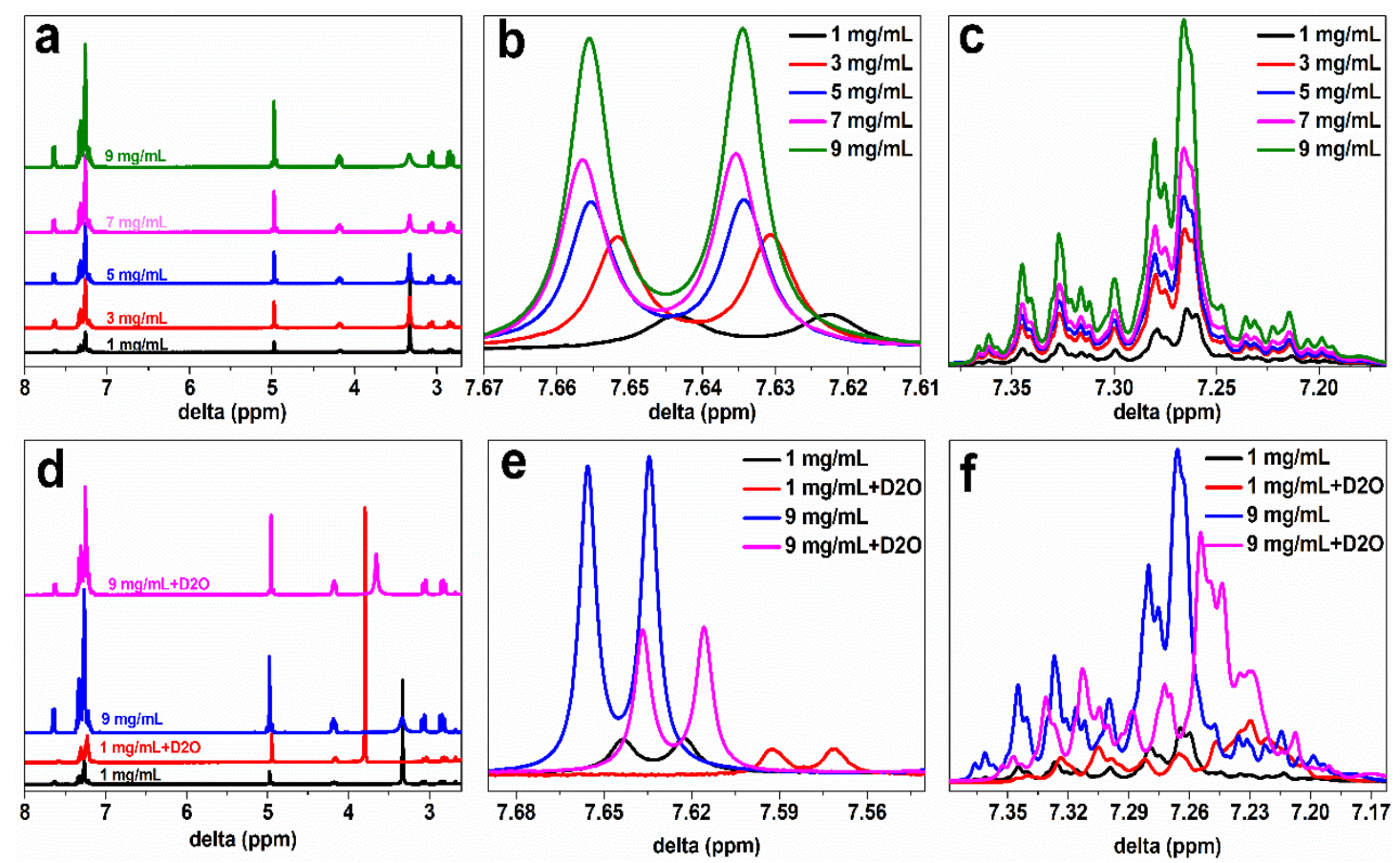

Figure 9: ${ }^{1} \mathrm{H}$ NMR spectra of Z-Phe-OH at concentration 1, 3, 5, 7, and $9 \mathrm{mg} / \mathrm{mL}$ in DMSO$\mathrm{d}_{6}$ (a) Full spectra; expansion in (b) 7.67-7.61 ppm; (c) 7.35-7.20 ppm; on addition of drop of $\mathrm{D}_{2} \mathrm{O}$ in DMSO- $\mathrm{d}_{6}$ sample (d) full spectra; expansion (e) 7.68-7.56 ppm; (f) 7.35-7.14 ppm.

To understand the mechanism of the self-assembly and structure formation we performed the concentration dependent ${ }^{36,37}$ liquid-state ${ }^{1} \mathrm{H}$ NMR..

The concentration-dependent ${ }^{1} \mathrm{H}$ NMR study was performed at concentrations $1,3,5,7$, and $9 \mathrm{mg} / \mathrm{mL}$ in DMSO- $\mathrm{d}_{6}$ at ambient temperature. The results revealed that as we increased the concentration, peak broadening was observed between $7.19-7.36 \mathrm{ppm}$ in the aromatic region, and no significant shifting. The $-\mathrm{NH}$ proton of carbamate group on the other hand shows significant deshielding as we increased the concentration of Z-Phe-OH from 1 to $9 \mathrm{mg} / \mathrm{mL}$ in DSMO- $\mathrm{d}_{6}$. The carbamate $-\mathrm{NH}$ proton shows the doublet at $7.63 \mathrm{ppm}$ in $1 \mathrm{mg} / \mathrm{mL}$ concentration whereas at $9 \mathrm{mg} / \mathrm{mL}$ this doublet shifted to $7.65 \mathrm{ppm}$ which may occur due to the presence of hydrogen bonding. To understand more about the self-assembled structure formation, we have added the drop of $\mathrm{D}_{2} \mathrm{O}$ in the DMSO- $\mathrm{d}_{6}$ sample and recorded the NMR 
spectra. The study demonstrated that the aromatic peak of Z-Phe-OH becomes shielded and shows the upfield shifting on the addition of $\mathrm{D}_{2} \mathrm{O}$. The aromatic peak in $1 \mathrm{mg} / \mathrm{mL} \mathbf{Z}-\mathbf{P h e}-\mathbf{O H}$ shows the peak at 7.17-7.37 ppm which shifted on the addition of $\mathrm{D}_{2} \mathrm{O}$ to $7.18-7.35 \mathrm{ppm}$ which clearly shows that there might be the presence of pi-pi stacking, also the main peak shifting from 7.26 to $7.23 \mathrm{ppm}$ which indicated the presence of pi-pi stacking in the aggregated state. There are various literature which suggest presence of pi-pi stacking causes upfield shifting of the peak as more aggregates are formed due to increased concentration. ${ }^{35}$, ${ }^{36}$ The details of peak shifting on increasing the concentration of Z-Phe-OH in DMSO-d ${ }_{6}$ and on the addition of a drop of $\mathrm{D}_{2} \mathrm{O}$ described in table 1 .

Table 2: NMR peak value of Z-Phe-OH in ppm in DMSO- $\mathrm{d}_{6}$ and on the addition of a drop of $\mathrm{D}_{2} \mathrm{O}$.

\begin{tabular}{|c|c|c|c|}
\hline $\begin{array}{c}\text { Concentration } \\
\text { of sample in } \\
\mathrm{mg} / \mathrm{mL}\end{array}$ & $\begin{array}{c}\text { Characteristic } \\
\text { peak }\end{array}$ & $\begin{array}{c}\text { Peak value (ppm) } \\
\text { In DSMO-d } 6\end{array}$ & $\begin{array}{c}\text { Peak value (ppm) after } \\
\text { addition of a drop of } \mathrm{D}_{2} \mathrm{O} \text { in } \\
\text { DMSO-d6 sample }\end{array}$ \\
\hline \multirow[b]{2}{*}{1} & Aromatic & $7.26(\mathrm{~m})$ & $7.23(\mathrm{~m})$ \\
\hline & $-\mathrm{NH}$ & $7.63(\mathrm{~d})$ & 7.58 (d) \\
\hline \multirow[b]{2}{*}{3} & Aromatic & $7.28(\mathrm{~m})$ & $7.26(\mathrm{~m})$ \\
\hline & $-\mathrm{NH}$ & $7.64(d)$ & 7.57 (d) \\
\hline \multirow[b]{2}{*}{5} & Aromatic & $7.28(\mathrm{~m})$ & $7.26(\mathrm{~m})$ \\
\hline & $-\mathrm{NH}$ & 7.64(d) & 7.60 (d) \\
\hline \multirow[b]{2}{*}{7} & Aromatic & $7.28(\mathrm{~m})$ & $7.25(\mathrm{~m})$ \\
\hline & $-\mathrm{NH}$ & $7.65(d)$ & 7.61(d) \\
\hline \multirow[b]{2}{*}{9} & Aromatic & $7.28(\mathrm{~m})$ & $7.25(\mathrm{~m})$ \\
\hline & $-\mathrm{NH}$ & $7.65(d)$ & 7.63(d) \\
\hline
\end{tabular}




\section{Conclusions}

In conclusion, we report the self-assembly of Z-Phe-OH, Z-Tyr-OH , Z-Trp-OH, and Fmoc-Tyr(tbu)-OH to the formed sphere and fibers like self-assembled structures at different concentrations and temperatures. The self-assembled structure formation has been characterized by optical microscopy, ${ }^{1} \mathrm{H}-\mathrm{NMR}$ spectroscopy. Our future endeavors will be focused to assess the self-assembly of Z-Phe-OH and Fmoc-Tyr (tbu)-OH in more detail by other spectroscopic and microscopic techniques.

\section{Materials and Methods}

General: All the modified amino acids were purchased from Sigma and used without further purification. The purity of all the amino acids procured was a minimum of $99 \%$. Deionized water was used for preparing all the solutions.

\section{Optical microscopy (OM):}

A $20 \mathrm{mM}$ stock solution of modified amino acids was prepared in $50 \%$ aqueous methanol solution while Fmoc-Tyr(tbu)-OH was prepared in only methanol due to its less solubility in aqueous methanol and given a sonication of 5 minutes to improve the solubility. Further, dilution was done using deionised water to prepare various concentrations of modified amino acids. These solutions turned into turbid solutions after some sometime which further indicated presence of assemblies in solution. The structures formed by self-assembly were observed under an optical microscope (OM) by drop-casting $20 \mu \mathrm{L}$ solution on a clean glass slide. Furthermore, the same solutions were heated at $70^{\circ} \mathrm{C}$ and then drop-casting of $20 \mu \mathrm{L}$ solution was done on a glass slide. The optical microscopy (OM) images were taken under Leica DM2500 upright fluorescence microscope with different magnifications and under different modes. The sample solutions were dried at room temperature before imaging. 
Concentration-dependent ${ }^{1}$ H NMR spectroscopy: The concentration-dependent ${ }^{1} \mathrm{H}$ NMR study was performed for Z-Phe-OH at 1, 3, 5, 7 and $9 \mathrm{mg} / \mathrm{mL}$ concentration in $\mathrm{DMSO}^{-\mathrm{d}_{6}}$ in subsequently drop of $\mathrm{D}_{2} \mathrm{O}$ addition by using $400 \mathrm{MHz}$ NMR instrument at $25^{\circ} \mathrm{C}$.

\section{Corresponding Author}

Department of Chemistry, Indrashil University, Mehsana, Gujarat, India; E-mail: gournidhi@gmail.com; nidhi.gour@indrashiluniversity.edu.in

\section{Funding Sources}

The work was supported SERB POWER Grant SPG/2021/000521 received by Dr. Nidhi Gour.

\section{Conflicts of interest}

There is no conflict of interest to declare.

\section{Acknowledgment}

NG, VK, and BK greatly acknowledge support from the SERB POWER grant (SPG/2021/000521) for funding and fellowships. BK thanks to SHODH scheme (Gujarat Government) for fellowship and Indrashil University for infrastructure support. VK is grateful to ICMR, India for providing financial support under the Senior Research Fellowship No.45/13/2020-/BIO/BMS.

\section{References}

1. Reches, M.; Gazit, E., Casting metal nanowires within discrete self-assembled peptide nanotubes. Science 2003, 300 (5619), 625-627.

2. Gazit, E., A possible role for $\pi$-stacking in the self-assembly of amyloid fibrils. The FASEB Journal 2002, 16 (1), 77-83.

3. Reches, M.; Gazit, E., Self-assembly of peptide nanotubes and amyloid-like structures by charged-termini-capped diphenylalanine peptide analogues. Israel journal of chemistry 2005, 45 (3), 363-371. 
4. Adler-Abramovich, L.; Vaks, L.; Carny, O.; Trudler, D.; Magno, A.; Caflisch, A.; Frenkel, D.; Gazit, E., Phenylalanine assembly into toxic fibrils suggests amyloid etiology in phenylketonuria. Nature chemical biology 2012, 8 (8), 701-706.

5. Zaguri, D.; Kreiser, T.; Shaham-Niv, S.; Gazit, E., Antibodies towards tyrosine amyloid-like fibrils allow toxicity modulation and cellular imaging of the assemblies. Molecules 2018, 23 (6), 1273.

6. Shaham-Niv, S.; Rehak, P.; Vuković, L.; Adler-Abramovich, L.; Král, P.; Gazit, E., Formation of apoptosis-inducing amyloid fibrils by tryptophan. Israel Journal of Chemistry 2017, 57 (7-8), 729-737.

7. Gour, N.; Kanth P, C.; Koshti, B.; Kshtriya, V.; Shah, D.; Patel, S.; AgrawalRajput, R.; Pandey, M. K., Amyloid-like structures formed by single amino acid selfassemblies of cysteine and methionine. ACS chemical neuroscience 2018, 10 (3), 1230-1239.

8. Koshti, B.; Singh, R.; Kshtriya, V.; Walia, S.; Bhatia, D.; Gour, N., Amyloid like aggregates formed by the self-assembly of proline and Hydroxyproline. 2021.

9. Roy, S.; Banerjee, A., Amino acid based smart hydrogel: formation, characterization and fluorescence properties of silver nanoclusters within the hydrogel matrix. Soft Matter 2011, 7 (11), 5300-5308.

10. Saha, A.; Bolisetty, S.; Handschin, S.; Mezzenga, R., Self-assembly and fibrillization of a Fmoc-functionalized polyphenolic amino acid. Soft Matter 2013, 9 (43), 10239-10242.

11. Patil, A. J.; Kumar, R. K.; Barron, N. J.; Mann, S., Cerium oxide nanoparticlemediated self-assembly of hybrid supramolecular hydrogels. Chemical Communications 2012, 48 (64), 7934-7936.

12. Perween, S.; Chandanshive, B.; Kotamarthi, H. C.; Khushalani, D., Single amino acid based self-assembled structure. Soft Matter 2013, 9 (42), 10141-10145.

13. Singh, P.; Brar, S. K.; Bajaj, M.; Narang, N.; Mithu, V. S.; Katare, O. P.; Wangoo, N.; Sharma, R. K., Self-assembly of aromatic $\alpha$-amino acids into amyloid inspired nano/micro scaled architects. Materials Science and Engineering: C 2017, 72, 590-600.

14. Singh, P.; Pandey, S. K.; Grover, A.; Sharma, R. K.; Wangoo, N., Understanding the self-ordering of amino acids into supramolecular architectures: co-assembly-based modulation of phenylalanine nanofibrils. Materials Chemistry Frontiers 2021, 5 (4), 19711981.

15. Singh, P.; Wangoo, N.; Sharma, R. K., Phenylalanine dimer assembly structure as the basic building block of an amyloid like photoluminescent nanofibril network. Soft Matter 2020, 16 (17), 4105-4109.

16. Koshti, B.; Kshtriya, V.; Nardin, C.; Gour, N., Chemical Perspective of the Mechanism of Action of Antiamyloidogenic Compounds Using a Minimalistic Peptide as a Reductionist Model. ACS Chemical Neuroscience 2021.

17. (22) Gour, N.; Gazit, E., Metabolite Assemblies: A Surprising Extension to the Amyloid Hypothesis. Curr Opin Chem Biol. 2021. (Just accepted)

18. Kshtriya, V.; Koshti, B.; Gour, N., Controlled Morphological Changes in SelfAssembled Structures Formed by Fmoc Variants of Threonine and Serine. 2021.

19. Gour, N.; Kedracki, D.; Safir, I.; Ngo, K. X.; Vebert-Nardin, C., Self-assembling DNA-peptide hybrids: morphological consequences of oligonucleotide grafting to a pathogenic amyloid fibrils forming dipeptide. Chemical Communications 2012, 48 (44), $5440-5442$.

20. Gour, N.; Verma, S., Bending of peptide nanotubes by focused electron and ion beams. Soft Matter 2009, 5 (9), 1789-1791. 
21. Gour, N.; Barman, A. K.; Verma, S., Controlling morphology of peptide-based soft structures by covalent modifications. Journal of Peptide Science 2012, 18 (6), 405-412.

22. Gour, N.; Mondal, S.; Verma, S., Synthesis and self-assembly of a neoglycopeptide: morphological studies and ultrasound-mediated DNA encapsulation. Journal of Peptide Science 2011, 17 (2), 148-153.

23. Barman, A. K.; Gour, N.; Verma, S., Morphological transition triggered by mannose conjugation to a cyclic hexapeptide. ARKIVOC 2013, 2, 82-99.

24. Abraham, J. N.; Gour, N.; Bolisetty, S.; Mezzenga, R.; Nardin, C., Controlled aggregation of peptide-DNA hybrids into amyloid-like fibrils. European Polymer Journal 2015, 65, 268-275.

25. Kedracki, D.; Filippov, S. K.; Gour, N.; Schlaad, H.; Nardin, C., Formation of DNA-Copolymer Fibrils Through an Amyloid-Like Nucleation Polymerization Mechanism. Macromolecular rapid communications 2015, 36 (8), 768-773.

26. Kshtriya, V.; Koshti, B.; Gour, N., Green synthesized nanoparticles: Classification, synthesis, characterization, and applications. 2021.

27. Kanth, P. C.; Verma, S. K.; Gour, N., Functionalized nanomaterials for biomedical and agriculture industries. In Handbook of Functionalized Nanomaterials for Industrial Applications, Elsevier: 2020; pp 231-265.

28. Gour, N.; Upadhyaya, P.; Patel, J., Nanomaterials as therapeutic and diagnostic tool for controlling plant diseases. In Comprehensive Analytical Chemistry, Elsevier: 2019; Vol. 84, pp 225-261.

29. Gour, N.; Kshtriya, V.; Gupta, S.; Koshti, B.; Singh, R.; Patel, D.; Joshi, K. B., Synthesis and Aggregation Studies of a Pyridothiazole-Based AIEE Probe and Its Application in Sensing Amyloid Fibrillation. ACS Applied Bio Materials 2019, 2 (10), 44424455.

30. Gour, N.; Kshtriya, V.; Koshti, B.; Gangrade, A.; Haque, A.; Bhatia, D., Synthesis and Characterization of the Fluorescent Self-Assembled Structures Formed by Benzothiazolone Conjugates and Applications in Cellular Imaging. 2021.

31. Kshtriya, V.; Koshti, B.; Gour, N., A New Azo Dye Based Sensor for Selective and Sensitive Detection of $\mathrm{Cu}$ (II), Sn (II), and Al (III) Ions. 2021.

32. Kshatriya, V.; Koshti, B.; Pandey, D. K.; Kharbanda, S.; Kanth, C. P.; Singh, D.; Bhatia, D. D.; Gour, N., Sequential and cellular detection of copper and lactic acid by disaggregation and reaggregation of the fluorescent panchromatic fibres of an acylthiourea based sensor. Soft Matter 2021.

33. Kshtriya, V.; Koshti, B.; Haque, A.; Gangrade, A.; Singh, R.; Joshi, K. B.; Bandyopadhyay, S.; Bhatia, D.; Gour, N.; Joshi, K. B., Self-assembly and photophysical studies of an unusual red colored dye which show green fluorescence in cell imaging. 2021.

34. Kshtriya, V.; Koshti, B.; Haque, A.; Gangrade, A.; Bandyopadhyay, S.; Bhatia, D.; Gour, N., Sunflower-like fluorescent self-assembled morphologies formed by pyridothiazole based aggregation induced emission (AIE) dye and its cell imaging applications. 2021.

35. Syamakumari, A.; Schenning, A. P.; Meijer, E., Synthesis, Optical Properties, and Aggregation Behavior of a Triad System Based on Perylene and Oligo (p-phenylene vinylene) Units. Chemistry-A European Journal 2002, 8 (15), 3353-3361.

36. Boccia, A. C.; Lukeš, V.; Eckstein-Andicsová, A.; Kozma, E., Solvent-and concentration-induced self-assembly of an amphiphilic perylene dye. New Journal of Chemistry 2020, 44 (3), 892-899. 